Article

\title{
Product Redesign for Service Considerations Using Affordances for Service Activities
}

\author{
Yong Se Kim ${ }^{1}{ }^{*}$, Kumiko Suzuki ${ }^{1}$ and Seok Jin Hong ${ }^{2}$ \\ 1 Creative Design Institute, Sungkyunkwan University, Suwon 16419, Korea; kumi020191@gmail.com \\ 2 Tres Works, Seoul 08375, Korea; sjhong@tres.kr \\ * Correspondence: yskim@skku.edu; Tel.: +82-31-299-6581
}

Received: 7 November 2019; Accepted: 23 December 2019; Published: 27 December 2019

\begin{abstract}
It is critical to design for affordances, which is the messages of products and services that help human activities when properly perceived, in both product design and service design. Although research on product design for user activities or user-friendly design has been conducted, few efforts have been dedicated to product design for diverse service considerations. In the context of servitization and product-service systems, many new services are devised starting with a product. A systematic method is proposed to redesign products so that value propositions through services can be enhanced by dealing with service activities specifically. By integrating service activities and product functions, affordances for service activities are identified. Affordance features for those affordances are designed and combined into the redesign of a product to support service activities. An illustrative case of a standing wheelchair redesign is described to validate the applicability of the proposed method for product redesign for service considerations. The proposed method enhances through the redesign of products diverse life-cycle services in which many stakeholders are participating to co-create values for societal, entrepreneurial, and ecological sustainability.
\end{abstract}

Keywords: affordances; design for services considerations; product redesign for service activities; charging services; standing wheelchair

\section{Introduction}

Product design must support user activities. Affordances, which is the messages provided by artefacts that induce natural activities of people when properly perceived, play critical roles in making interactions successful and meaningful [1,2]. This notion of affordances reflects both that of Gibson [1] and Norman [2]. Galvao and Sato [3] suggested a shift from the traditional product-centred approach to the user-centred approach using affordances to support user-friendly product design. They developed a systematic method to identify affordances using the relationships between product functions and user tasks $[4,5]$. User tasks are composed of user activities. The notion of affordance features, structural elements of artefacts that provide affordances, has been proposed by researchers in feature-based design including Murakami and his co-authors [6,7]. While affordance features exist inherently as properties of artefacts, as argued by Gibson [1], proper perception of those affordance features depends on user's capability and experiences as emphasized by Norman [2]. A methodological framework for design for affordances has been proposed wherein a repository of affordance features is used [8]. The key for this affordance method design is to compile affordance features in the repository so that new affordance feature design can exploit previous affordance features in the repository.

Although research on product design for user activities, or user-friendly design, has been conducted, few efforts have been devoted to design for service activities. As life-cycle issues during product use, activities of other stakeholders than product users include various service activities including repair and maintenance activities. Design for serviceability [9-11] addressed design 
guidelines for ease of repair and maintenance as well as support logistics as a part of overall product life-cycle design method [12,13] including design for manufacture [14], design for assembly, and design for disassembly [13]. Most "design for X" methods provide generally accepted design rules involving product structure and material issues [13,14]; in other words, most existing design for serviceability methods are product-centred, not user-centred. Services addressed in these "design for $X$ " methods are more conventional services to ensure continued use of products such as maintenance, repair, disassembly, and reassembly. Although such service activities are performed by other stakeholders than users, serviceability is linked with users and owners as well because it is related with the cost of ownership and use in association with perceived product values [10].

In the context of servitization [15-17] and product-service systems [18-20], which recently has received considerable attention, services address recently diverse value proposition efforts including customer experience services [21,22], consulting services, education services, financial services, rental and sharing services, recycling services, and disposal services. $[23,24]$. In this way, the significance of services has been expanded and the variety of services has vastly increased. In most servitization efforts, these services are devised after product design and development have been conducted. Accordingly, research on the methods to redesign products with specific considerations on service activities is desired. Moreover, it is desirable to devise these methods in a human-centred design approach, in which diverse service activities can be specifically addressed as new services are designed. Note that development of product-centred design guides for all such new services would be more difficult.

Kim developed a method to design product elements of product-service systems so that associated service activities can be specifically and naturally induced using affordances and affordance features [25]. Note that the product elements in this method are new product elements that needed to be newly devised to support new services, not the product around which product-service systems are devised. For example, the provision and retrieval structures for an umbrella rental product-service system are the product elements, not the umbrellas. Functions of product-service systems are integrated with service activities to identify affordances for service activities. Some activities are done by users and some are performed by service-providers. For example, medical devices like wheelchairs should be designed for users and for diverse service providers who provide operation, maintenance, and repair services during the use phase of the product. Once product design has been done, taking into consideration user activities, further design, or redesign, considerations should be given to support service activities. Because many new services that are newly created in product-service systems start with a product, a systematic method to redesign the product for those new services in a service provider centred approach needs to be devised by addressing the aspect of service activities specifically and extensively.

In this paper, a method for product redesign for services activities is proposed and an illustrative case of a standing wheelchair redesign is described to validate the applicability of the proposed method for product redesign for service considerations. In the next section, the design for affordance framework is briefly reviewed because it forms the underlying method. In Section 3, the proposed product redesign process for service activities is described. Next, the case of redesign of a standing wheelchair for charging service is presented. The paper concludes with discussions on the contribution of the paper and further research.

\section{Design for Affordance Framework}

The framework of design for affordances using affordance feature repository [8] is briefly reviewed. Firstly, affordances are identified for the given design problem. Using the Function-Task Interaction (FTI) method [3,4], affordances can be identified by integrating user activities and functions of the product or the service. The output of the first step is the list of affordances. The first step is marked by (1) in Figure 1, illustrating the framework of design for affordance. Secondly, using the repository of affordance features where multiple affordance features for a given affordance are compiled, affordance features for each affordance identified in Step 1 are browsed as marked by (2) and (3) in Figure 1. 
Next, affordance features of the identified affordances are selected considering design constraints and context of those in the repository so that those affordance features with design constraints and context similar to the current design constraints and context are used in the subsequent process, as noted by (4) in Figure 1. The second step includes the selection of affordance features in the repository. Thirdly, using the clues given by the selected affordance features, a new affordance feature is designed through analogical reasoning. The last step in this framework is then the analogical reasoning step that converts the source affordance features in the repository into the target affordance features to support the affordances of the current design problem, as noted in Figure 1 as the transformation from (4) to (5).

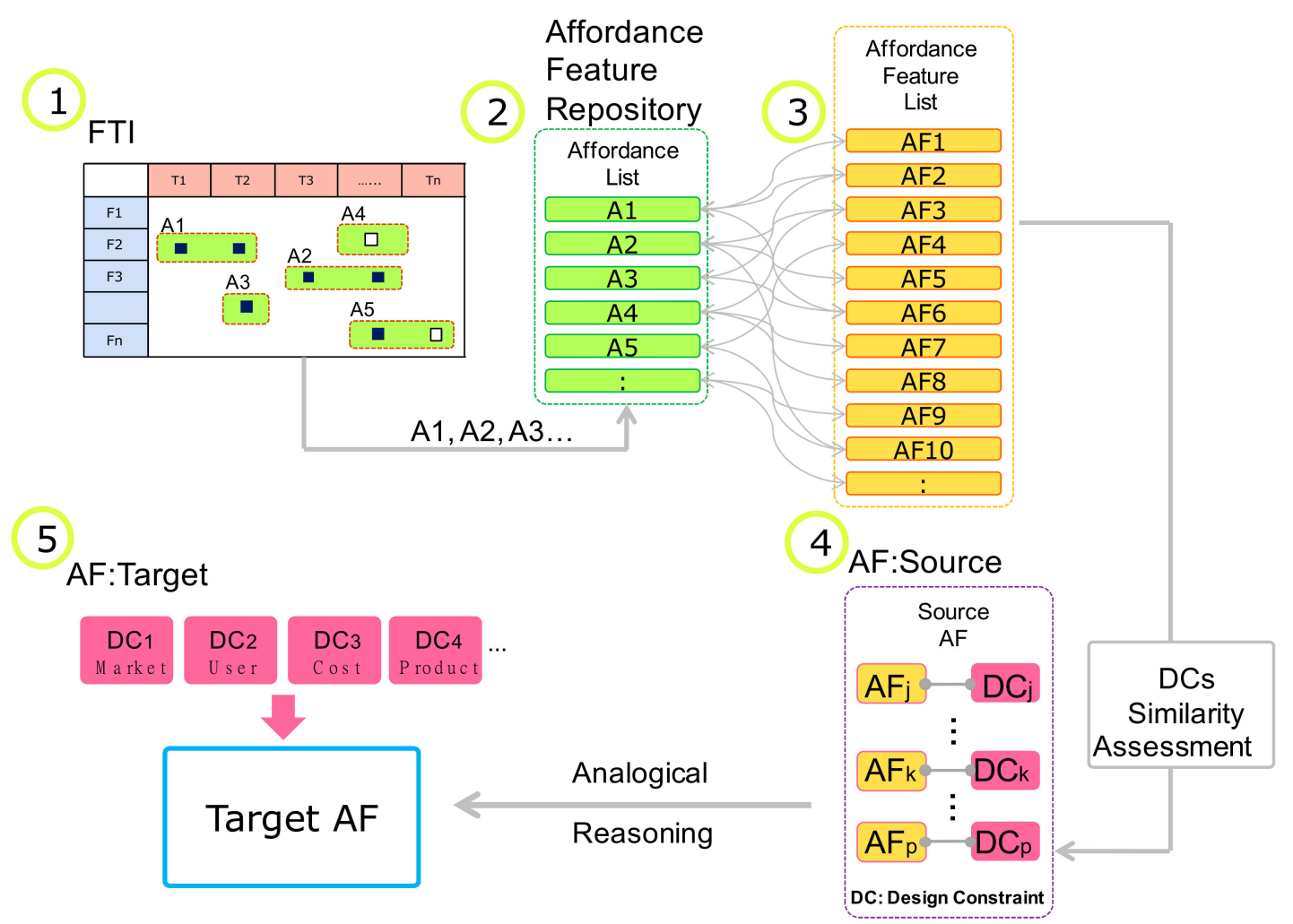

Figure 1. Design for Affordance Framework [8].

\section{Product Redesign for Service Activities}

The proposed product redesign process for service activities is described in this section, as shown in Figure 2. The activities of the service for which redesign of product is to be pursued are identified, including those of users and of service providers. This corresponds to the process of the right lowest step of Figure 2. These activities are represented using a service blueprint in which the interaction between the receivers and the providers of services is represented [26]. Key activities in the service blueprint are modeled using the context-based activity modeling (CBAM) method [27] with rich descriptions using the activity elements and the context elements. In the CBAM method, an activity is represented with the activity elements of the actor, the object, the action verb, the tool, and the context. The context is then represented with the context elements of the goals, the relevant structures, the physical contexts, and the psychological contexts [27]. Specific affordance features in the repository also contain specific information on these activity elements and context elements. Note that this information is critical in devising target affordance features through analogical reasoning [8] to be conducted in the following processes. 


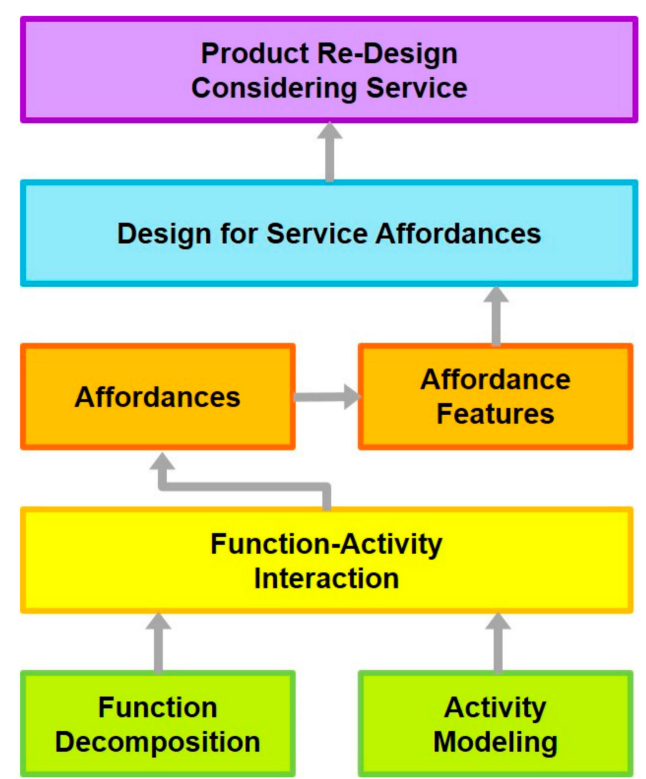

Figure 2. Product Redesign Process for Service Activities.

The functions of the product are identified in a hierarchical manner with a function-based design method [28,29], as noted with the process of the left lowest step of Figure 2. Here the functions related with the service activities are decomposed further in detail. By integrating product functions and corresponding service activities noted as the second lowest step of Figure 2, affordances are identified using the FTI method [4,5], noted as the left middle step of Figure 2. The product redesign is to design for these affordances. The product redesign is to done in a "divide and conquer" manner by synthesizing affordance features designed for these affordances.

Then, as noted in the right middle step of the figure, multiple affordance features are selected from the affordance feature repository for each of the affordances so that they are used as source affordance features in the subsequent analogical reasoning process. Target affordance features for service activities are devised, as noted by the second topmost step of the figure, considering the context and constraint of the product by analogical reasoning from the source affordance features selected from the repository [8]. Here the detailed descriptions of the relevant activities with the CBAM method play important roles. Although the source affordance features support the relevant affordances, the specific incidences of the activities of the source features have their own activity elements and context elements, which would be different from those of the desired service activities. The process of this analogical reasoning is one of the key creative processes and is supported by the CBAM method. The redesign task of product for service activities has been divided into affordance feature design of the affordances. For each affordance, multiple alternative affordance features are to be devised so that suitable affordance features are selected in the desired solution. This aspect will be described further in the case study with specific examples.

Now the redesign of product is to be done by synthesizing the affordance features of all these affordances in the divide and conquer approach. As the desired redesign of product will combine these target affordance features, multiple overall redesign alternatives are generated using morphological analysis of the affordance features. Morphological analysis [30] is a problem-solving approach that decomposes the problem into sub-problems. Design concepts for sub-problems are combined to develop many alternative overall solutions of the problem. Morphological analysis has been used in concept generation with exploration of possible concept alternatives [31]. Recently, morphological analysis has been used in business model strategy design [32,33] and conceptual design for product-service systems [34]. Then the final concept design is selected by evaluating the alternative designs based on various evaluation criteria using, for example, the Pugh's concept selection method [35]. Evaluation criteria are obtained through requirement identification and user research, addressing diverse values 
for users and service providers considering product use and service activities. In this way, product redesign is conducted considering service activities specifically.

In typical servitization efforts based on product-service systems, new service concepts are designed after the product has been designed. Redesign of product for service activities is therefore deeply associated with the design process of service activities. As newly devised services become complex and comprehensive, involving many stakeholders as is often the case of many recent servitization, the proposed product redesign method for service activities provide systematic structured supports in redesigning the product as long as the activities of new service concepts are properly designed using the CBAM method.

\section{Case: Redesign of Standing Wheelchair for Charging Services}

To illustrate the method for product redesign for service activities outlined in Section 3, the case study of redesign of a standing wheelchair, as shown in Figure 3, is described in this section. Standing wheelchairs are relatively newly developed, reflecting desires of those wheelchair users in standing and/or working. Note that the visibility, reachability, and accessibility of wheelchair users would be tremendously expanded with the standing function. However, due to their infancy in real-world usage, the current design of the manufacturing company is limited in supporting service activities. Particularly, this case study addresses the activities of charging that could be viewed as a service function. As the key lifting function of the standing wheelchair requires a significant amount of energy, charging needs to be conducted quite often. With the current design, a service provider or care giver would find charging not so convenient. Wheelchair users cannot charge themselves. Thus, a redesign that considers charging activities is crucial for this product to be properly used both in daily life or in a working context. The step-by-step processes of the proposed redesign method for service considerations as applied to this case are explained in the following subsections.
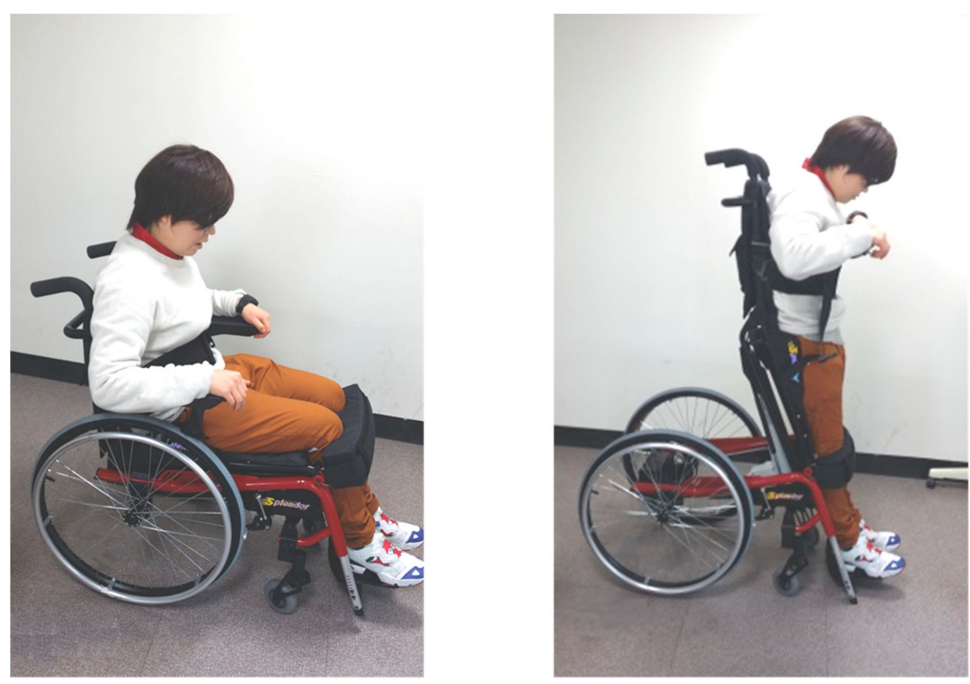

Figure 3. Standing wheelchair.

\subsection{Activity Modeling: Use and Service Activities of a Standing Wheelchair}

The use and service activities of the standing wheelchair including battery charging by a help service provider have been identified and represented in the service blueprint as shown in Figure 4 . The move service unit shown in blue describes the activities of the user and the helper in the unit. The user tells the destination and the helper pushes the wheelchair to move the user. The standing and descending unit in lime color describes the user activities in controlling the wheelchair in the standing function. The charging service unit in yellow shows the interactive activities of the user and a charging service provider including moving to a power outlet and connecting a battery to the outlet by using an adaptor. The use finish unit in grey is about getting off from the wheelchair, finishing the use. 


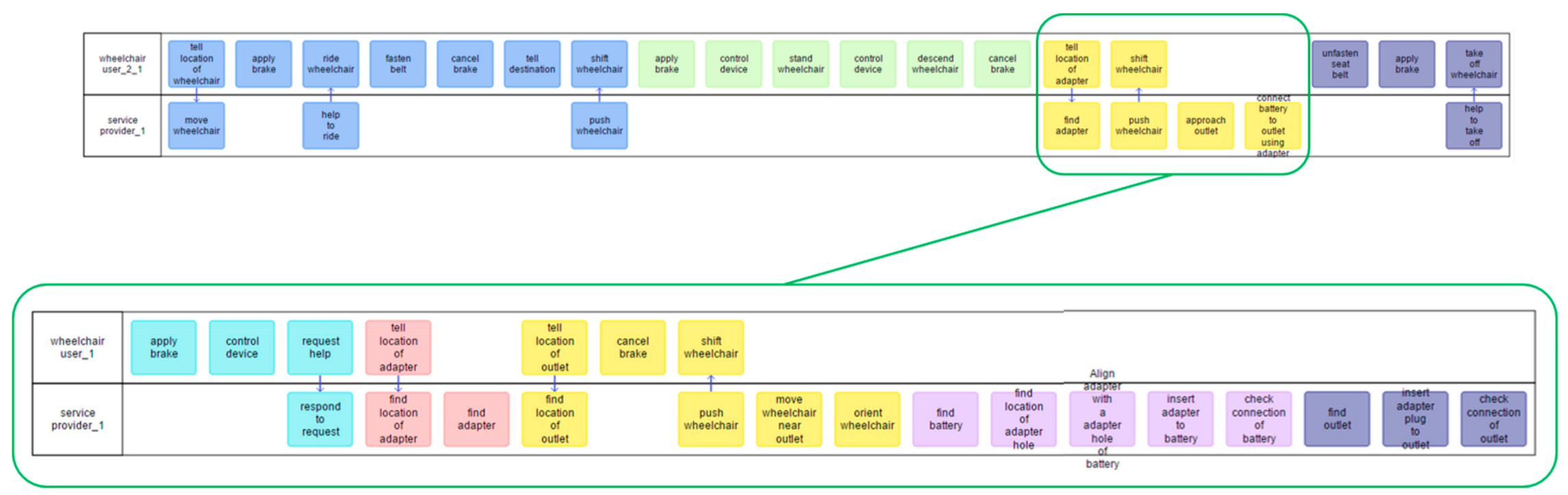

Figure 4. Service Blueprint for a Standing Wheelchair. 
The charging service unit is to be represented in more detail. Note that the wheelchair needs to be properly oriented so that the helper may have accessibility to insert the adapter plug into the hole in the battery and connect it to the outlet once the wheelchair is moved near an outlet. Inserting the adapter plug into the battery hole requires aligning them properly, which is a dexterous activity. Such activities of plugging in are followed by ensuring proper connection. Note the battery charging is supposed to be done often as lifting requires much energy. While the battery charging is done by connecting the adapter between the battery and the outlet, if the adapter plug is to be inserted at a more accessible location, charging can be more easily accomplished.

As shown in the lower, detailed service blueprint in Figure 4, the charging service unit is represented in detail with five service elements of (1) the requesting element shown in light blue color, (2) the finding adaptor element in pink, (3) the approaching to outlet element in yellow, (4) the element of connecting the adaptor and the battery in purple, and (5) the element of connecting the adaptor to the outlet in grey. As the charging service with the current product design of the wheelchair needs to be improved, the redesign of the wheelchair is to be conducted using the proposed design method considering charging service activities.

The context and the constraints of the redesign task can be addressed using the CBAM method [23]. The CBAM description of the charging activity would have the service provider as the active actor, the user as the third party actor, to connect as the action verb, the battery and the outlet as the object, and the adapter as the tool. The context elements include the goal context of charging and the relevant structures of the wheelchair and the structures surrounding the power outlet. The physical context includes the location and the time. The psychological context includes the occupant context of the user and the service provider as well as others present in the scene, the privacy context of public activity, as well as other psychological issues. The CBAM descriptions for lower level activities would also be utilized in redesigning of the wheelchair.

\subsection{Function Decomposition}

The main function of a standing wheelchair that is relevant to the new standing function is discussed in this redesign for service activities, not the basic functions of a standard wheelchair. This includes the following functions: to support the body, to stand (or lift), to descend the body, and to provide energy and to charge the battery, as shown in Figure 5a. Note that providing energy and charging the battery functions are related with standing and descending functions as these functions are enabled with the energy charged and stored in the battery. In addition to standing and descending the body, to move the body is a key function of the wheelchair; however, this is not described because moving is not operational at the same time as standing and descending functions. As pre-use and post-use functions, attaching and detaching the battery are also described in Figure 5a as well as supporting the battery as a part of the wheelchair during the overall use phase.

Note that the function to supply energy is composed of charging, storing, and providing energy. The charging function marked with dotted lines in Figure 5a has been decomposed, as shown in Figure $5 \mathrm{~b}$. The battery and the power outlet is connected with human energy for charging the battery. In charging the battery, the adapter is used; this is represented with dotted lines in the lower portion of the figure, with the two functions of connecting the battery and the adaptor and connecting the adaptor to the outlet as decomposed from the function of connecting the battery to the outlet. 


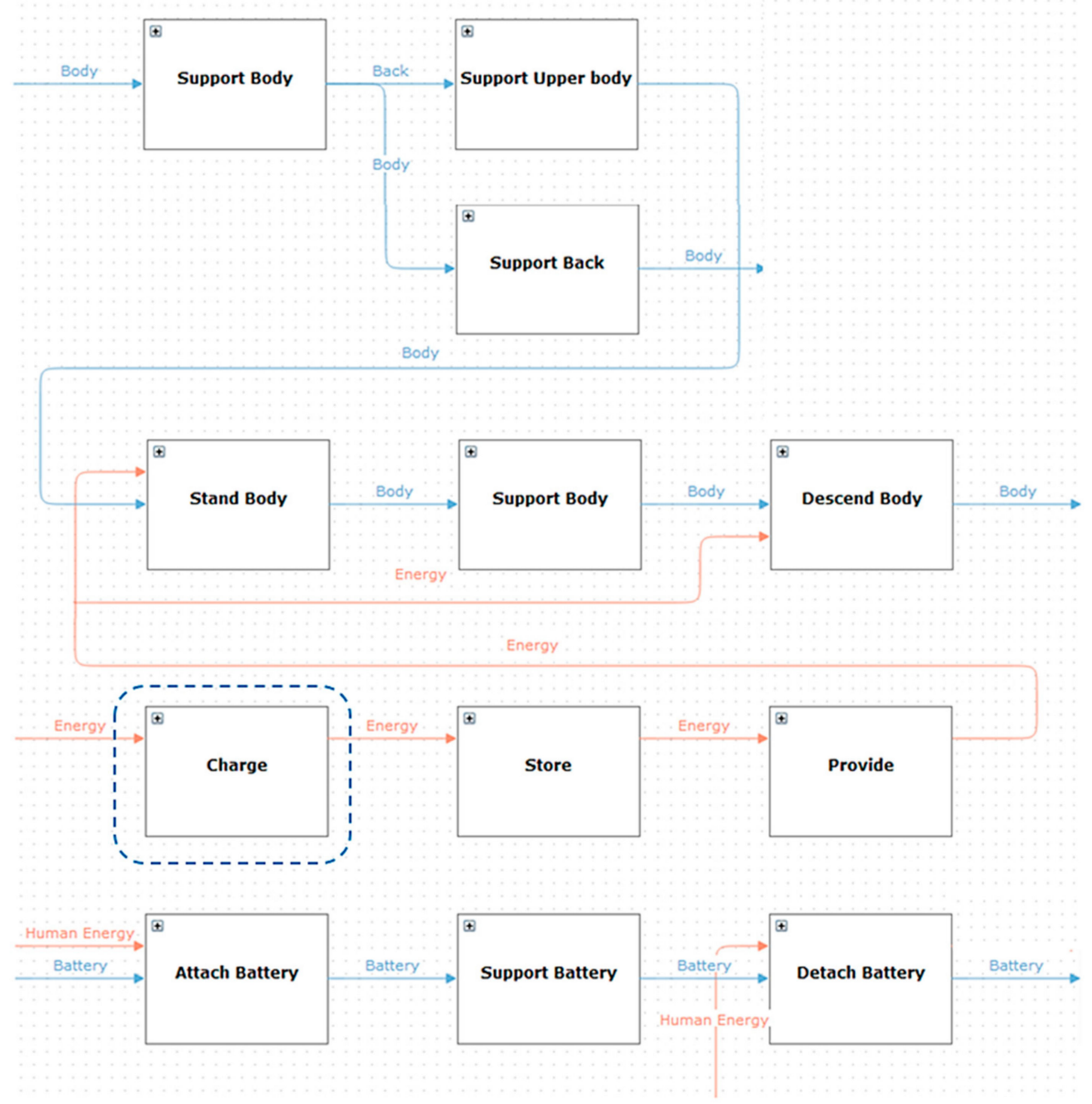

(a)

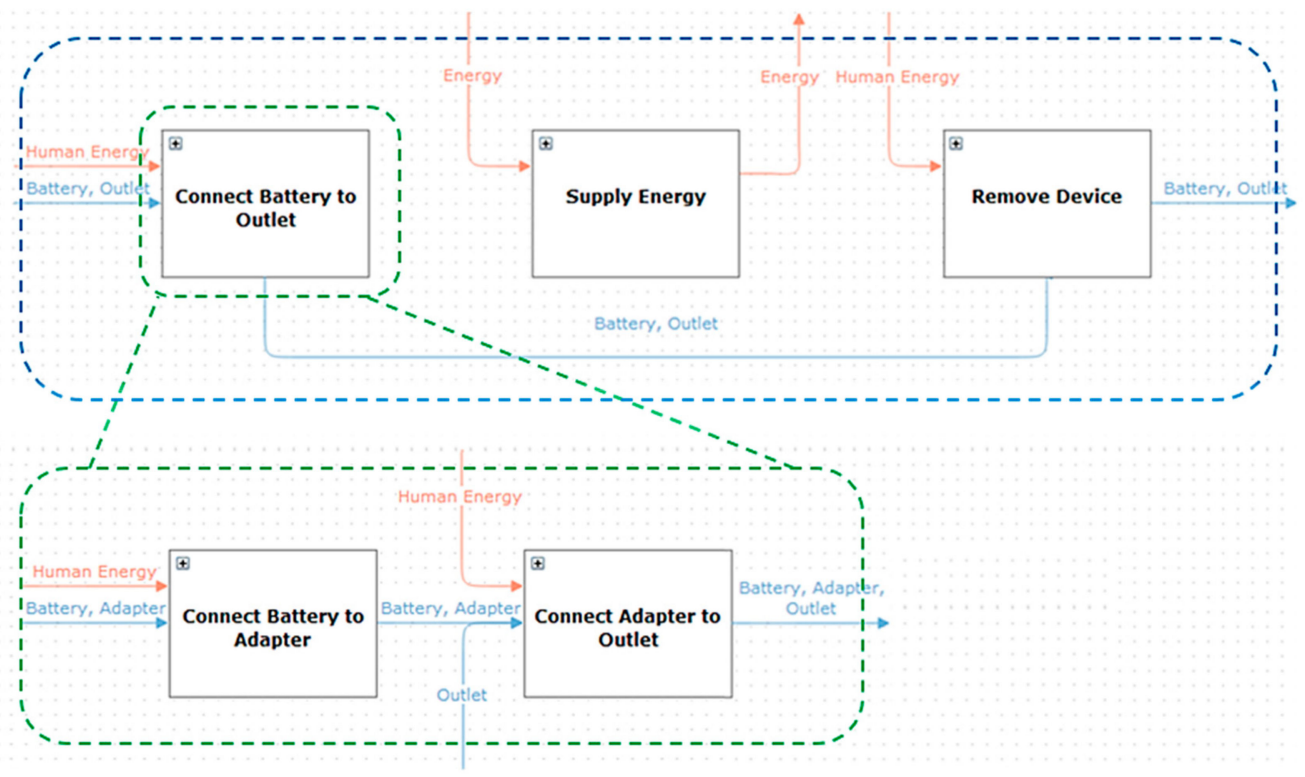

(b)

Figure 5. Function Decomposition of a Standing Wheelchair. (a) Decomposition of Functions relevant to Standing Function. (b) Decomposition of Charging Function. 


\subsection{Function-Activity Interaction and Affordances}

By interrogating cognitive and physical relations of the charging functions and corresponding activities in the service blueprint, the affordances in human activities of charging service are identified and shown in Figure 6. For connecting the adapter to the battery, five affordances of find-ability, access-ability, align-ability, insert-ability, connect-ability, and check-connection-ability are identified. For plugging the adapter to the outlet, four affordances of find-ability, insert-ability, connect-ability, and check-connection-ability are found.

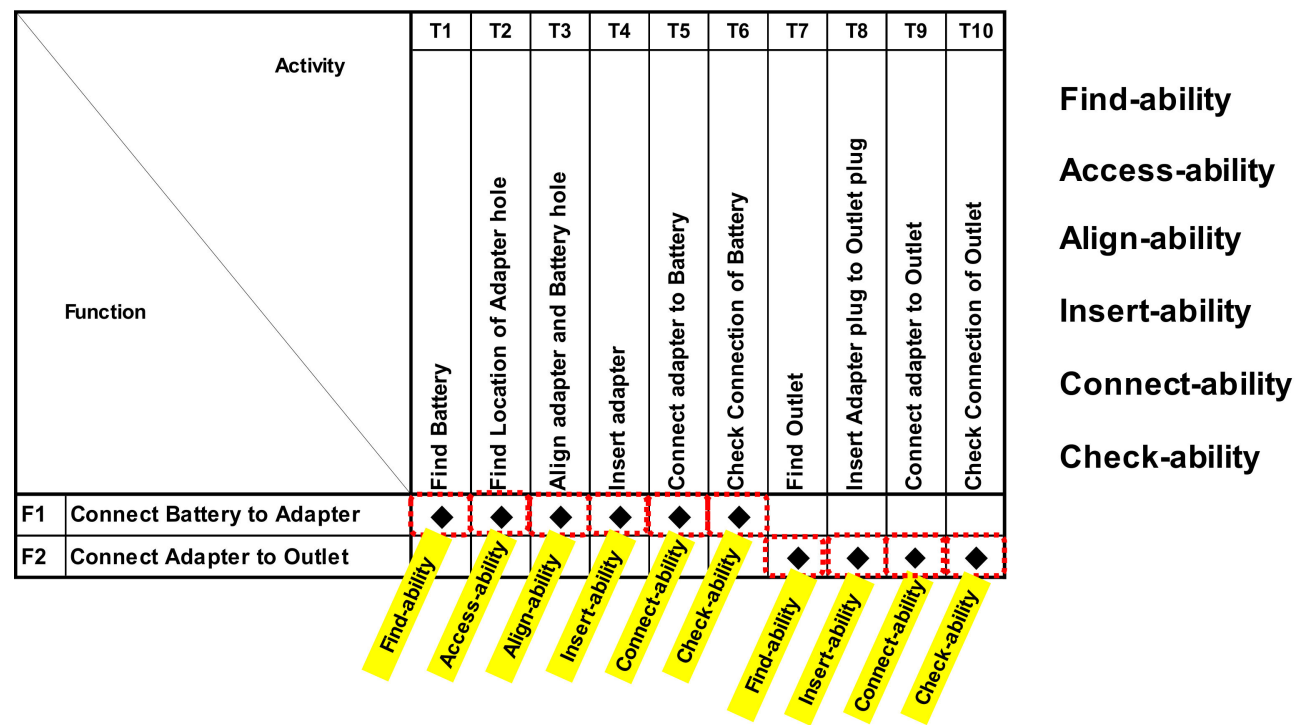

Figure 6. Function-Activity Interaction and Affordances for Charging Service of the Standing Wheelchair.

\subsection{Design of Affordance Features}

For the affordances identified in the previous subsection, affordance features are selected from the repository as source affordance features, from which target affordances features suitable for the context of wheelchair battery charging can be devised through analogical reasoning.

\subsubsection{Find-ability Affordance Features}

In the current design, the battery is located under the back support and between two wheels near the hydraulic cylinder. Thus, both visibility and accessibility to the battery in charging are extremely poor. The find-ability affordance is to support the activity of finding the battery and the power outlet to connect the adaptor as identified in the function-activity interactions shown in Figure 6. From the repository, three find-ability affordance features were identified, as shown in Figure 7a. Note that the find-ability affordance is a visceral affordance of the three kinds of visceral, behavioral, and reflective affordances [36]. Among the perception, decision-making, and action components of an activity, the perception part is dominant in the activity of finding; accordingly, visceral affordance relying on sensorial interaction is relevant. 


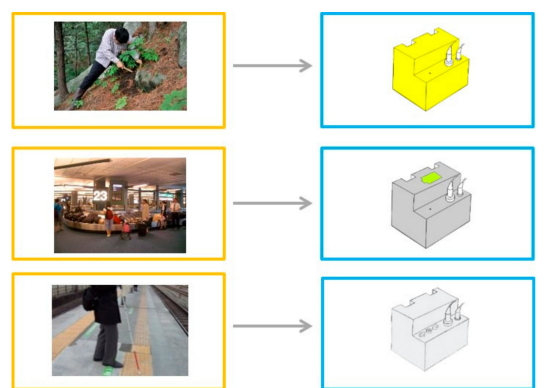

(a)

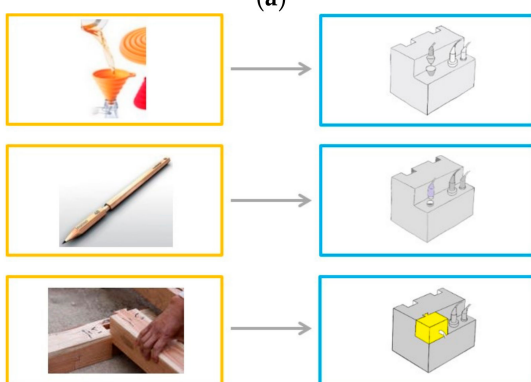

(c)

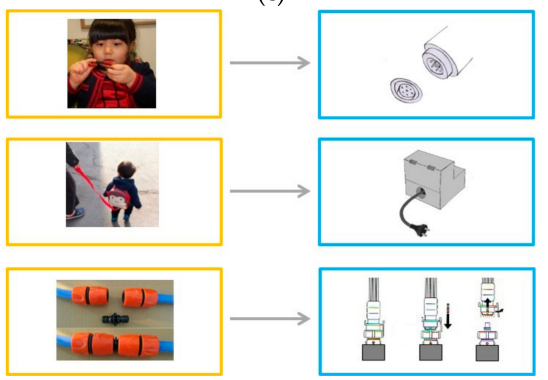

(e)

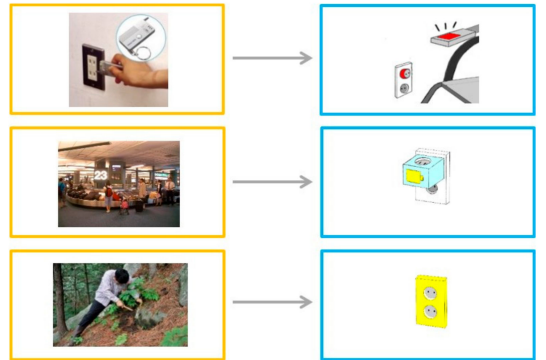

(g)
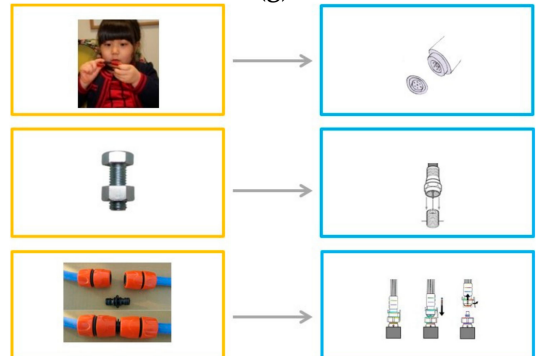

(i)

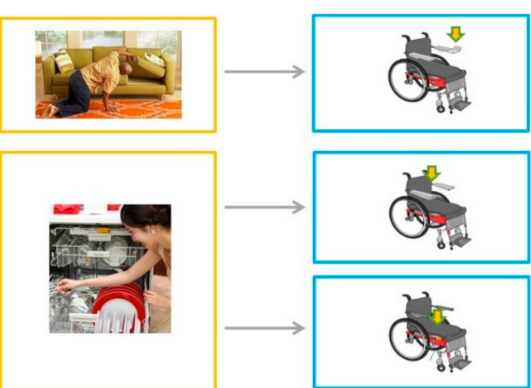

(b)
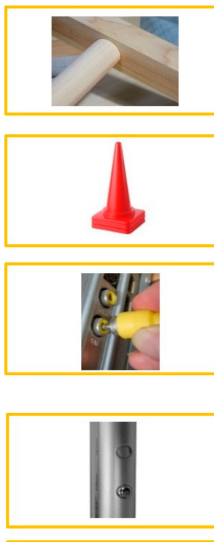

(d)

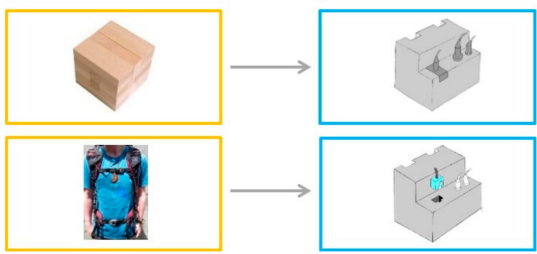

(f)
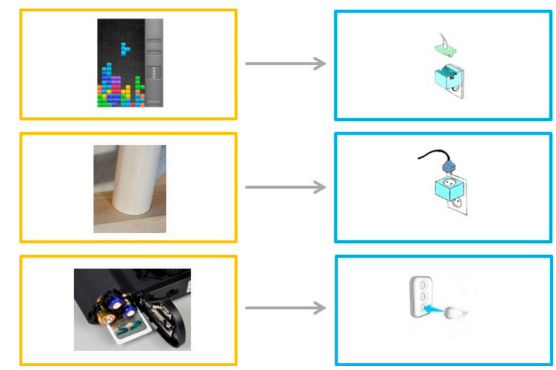

(h)

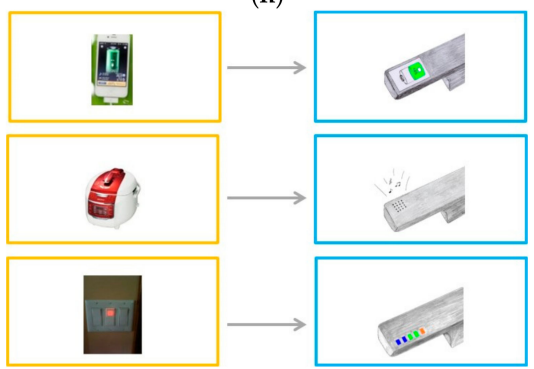

(j)

Figure 7. Affordance Features. (a) Find-ability (Find the Battery). (b) Access-ability (Find Location of the Adapter hole). (c) Align-ability (Align the Adapter and the Battery hole). (d) Insert-ability (Insert the Adapter). (e) Connect-ability (Connect the Adapter to the Battery). (f) Check-ability (Check Connection of the Battery). (g) Find-ability (Find the Outlet). (h) Insert-ability (Insert the Adapter plug to the Outlet). (i) Connect-ability (Connect the Adapter to the Outlet). (j) Check-ability (Check Connection of the Outlet). 
The first source affordance feature in Figure $7 \mathrm{a}$ affords the finding activity with a distinctive color of leaves for the visceral level of interaction. The target find-ability affordance feature for the battery charging context is the battery colored in yellow to maximize visceral distinction from black/grey components of the wheelchair. The second find-ability feature in Figure $7 \mathrm{a}$ is the colored name-tag of a large bag in the baggage carousel of an airport. The corresponding target find-ability feature is the yellow tag attached near the connection area of the grey battery. The third find-ability feature is the protrusion used for blind people so that these can be perceived with their mobility aid sticks, as shown in Figure 7a. The corresponding target find-ability feature is the protruding hole of the battery for tactile sensory interaction.

The other interaction incidence of the find-ability affordance is the ability to find the power outlet to connect the adaptor, as shown in Figure $7 \mathrm{~g}$. The first source feature is the use of a sensor so that a beeping sound and/or a blinking light is ignited if a tag is near enough to the sensing pad. In its corresponding target feature, a sensor is used to beep and/or to light on if the wheelchair and the adaptor connector are close enough to the power outlet, as shown in Figure $7 \mathrm{~g}$. The second and the third target features use the colored tag and the colored body of the power outlet respectively using the same source features of the find-ability affordance of Figure $7 \mathrm{a}$.

\subsubsection{Access-ability Affordance Features}

The access-ability affordance is to have access to the adaptor plug hole of the battery. The first source access-ability feature shown in Figure $7 \mathrm{~b}$ is the lifted covering. The second source access-ability feature is the visible dishes that allows for vertical downward access. Noting that the controller located at the hand rest of the current wheelchair design is connected to the battery, the adapter plug hole can also be located at the hand rest. Exploiting this specific context information of the wheelchair, the target access-ability features are devised, as shown in Figure $7 \mathrm{~b}$. The plug hole can be located under a cover at the hand rest as shown in the first feature in Figure $7 \mathrm{~b}$. The second is located on the top surface of the hand rest allowing vertical downward access. The third one is located near a wheel with vertical downward visibility and access.

\subsubsection{Insert-ability Affordance Features}

Two incidences of insertion activities are relevant in the charging service: insertion of the adaptor plug into the battery hole, as in Figure $7 \mathrm{~d}$, and inserting of the power plug of the adaptor into the power outlet, as in Figure $7 \mathrm{~h}$. A peg and a hole insertion features were selected once in each of the two insertion cases. A peg and a hole target feature with direct analogy is devised for the insertion of the adaptor into the battery hole, as shown in the first target feature of Figure 7d. For the case of the adaptor and the outlet insertion, a connection unit which changes the insertion orientation from horizontal to vertical direction is added so that the downward vertical insertion of the adaptor plug is possible, as shown in the second target feature of Figure $7 \mathrm{~h}$. A pair of nested cones as a source feature, shown in the middle of Figure 7d, is directly applied in the target feature for the insertion of the adaptor into the battery hole. For the third feature, for the case of insertion of the adaptor into the battery hole, a typical data connection feature is selected and the analogical target feature is made with direct analogy, as shown in Figure $7 \mathrm{~d}$. Note that the target features of the insertion case of the adaptor and the battery hole are all obtained with direct analogy.

On the other hand, the first source feature for the case of power outlet insertion is the Tetris insertion, as shown in Figure $7 \mathrm{~h}$. The target feature uses a 2.5 dimension version of this Tetris feature, with conversion of the insertion direction to the downward vertical direction. The last source feature is the cartridge, which is composed of three sub-pieces so that the insertion of the cartridge achieves insertion of the sub-pieces. The target feature is composed of the modification on the adaptor by consolidating adaptor plug protrusions into a single protrusion with the add-on mating component on the outlet inserted beforehand. This consolidating protrusion makes the rotational symmetry angle of 
insertion [37] zero degree achieving great reduction in assembly cost. Note that its insertion direction is still horizontal in this target feature.

\subsubsection{Connect-ability Affordance Features}

Affordance features for connecting the adaptor to the battery and to the power outlet are required in the charging service, as shown in Figure 7e,i, respectively. Use of magnets, the attached connected string, and the connector for water hoses are source features in Figure 7e. A fastening connection appears as a source feature in Figure 7i as well as the magnets and the water hose connector. Direct analogy target features are devised as shown in their respective figures.

\subsubsection{Connection Check-ability Affordance Features}

Check-ability for a connected state is needed for connections between the adaptor and the battery and between the adaptor and the outlet. For the former connection, the source features are the lighting indicator, the flushed surfaces of fully mated components, and the clipping sound for a clip fastener. Direct analogies are done for the target features, as shown in Figure 7f. For the latter, the green color image with the level of charging state on a phone screen is the first source feature, as shown in Figure 7j. Its target is to show the corresponding image on the hand rest. The second source is the ding sound made when a power plug of a rice cooker is plugged, as shown in the middle of Figure 7j. A similar ding sound for a connecting check, which comes from a speaker located in the hand rest, is the corresponding target feature. The level indicating light of the source can be shown in the hand rest as the target feature, as shown in Figure $7 \mathrm{j}$.

\subsection{Morphological Analysis for Product-Redesign for Charging Service}

The morphological chart with three alternative affordance features for each of the ten affordances has been constructed, as shown in Figure 8. By combining these affordance features, a lot of the redesign concept alternatives can be generated. In this example of the standing wheelchair, four alternative redesign concepts of A, B, C, and D, as shown in Figure 9, have been devised. While the overall redesign problem has been decomposed into 10 design for affordance sub-problems, with multiple candidate affordance features for each affordance, overall redesign concepts that combine the affordance features for 10 affordances might involve conflicting features. Also, more than one affordance features could be selected for an affordance level. In general, the overall concept design task requires creative synthesizing, more than just the summing up of affordance features as in the case of typical divide-and-conquer approaches.

Concept A adopts the colored battery connecting unit located near a wheel, and the adaptor plug unit incorporates a sensor for nearby tagging and the consolidated insertion unit with horizontal insertion direction. Concept B has the small but yellow-colored battery-connecting unit on both of the hand rests with funnel-like aligning features and the adaptor plug unit with vertical downward insertion. Concept C's battery connecting unit is located on the hand rests with the slot-mating alignment features with flushed surface indicators for confirmation of the proper connected state. The outlet connecting unit combines two insert-ability features of the consolidated protrusion and the add-on feature with the vertical downward insertion direction. Concept $\mathrm{D}$ has the battery connecting unit of the colored insertion feature with the string coming from the hand rests. The outlet connecting unit has the vertical downward insertion feature with 2.5 dimensional Tetris-like insertion mating. 

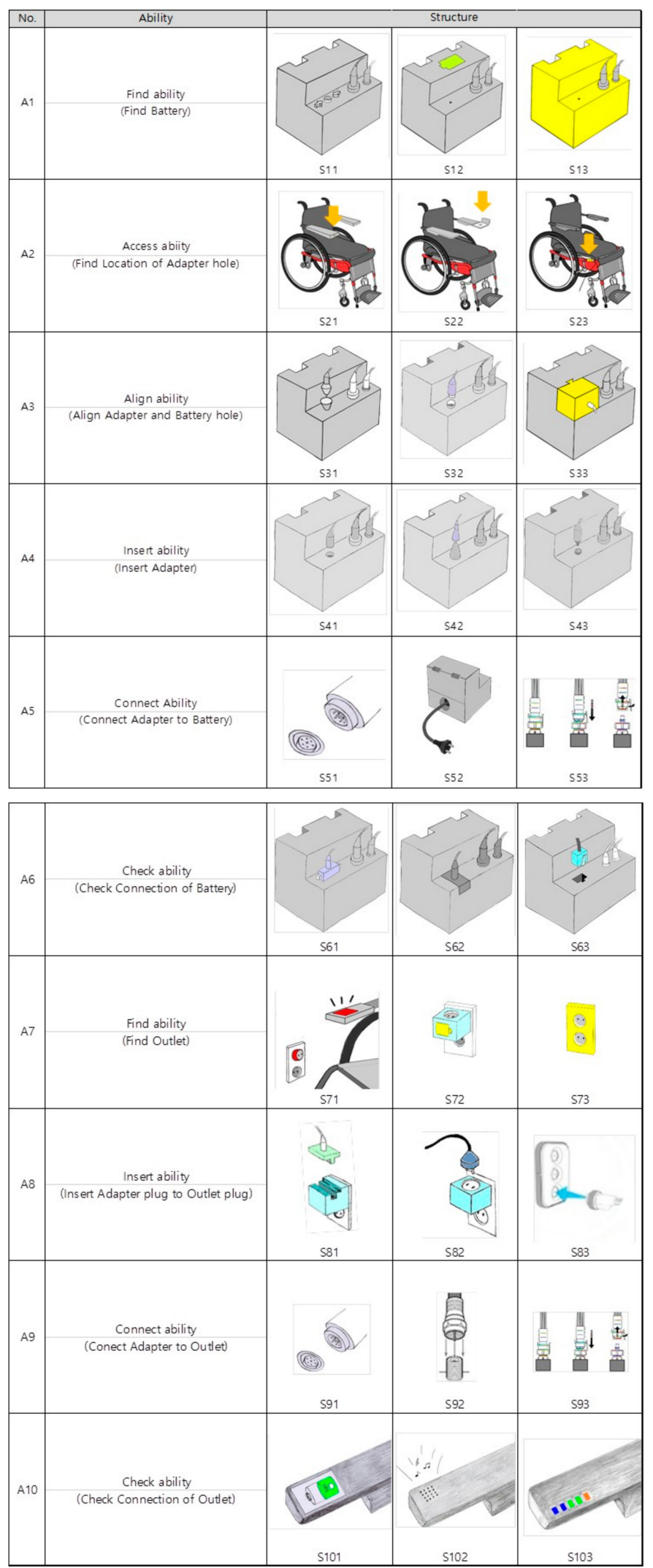

Figure 8. Morphological Chart with Affordance Features. 

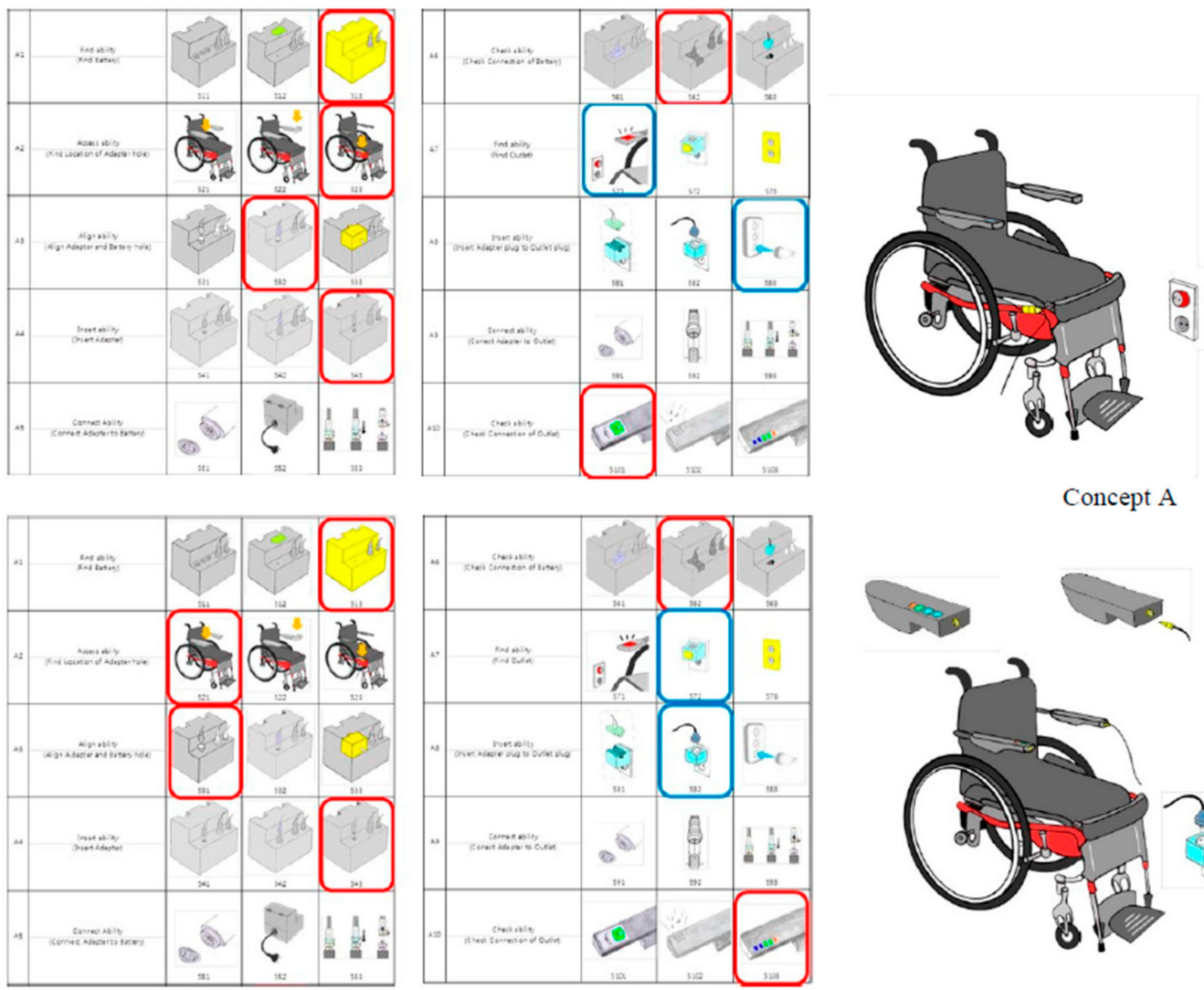

Concept A
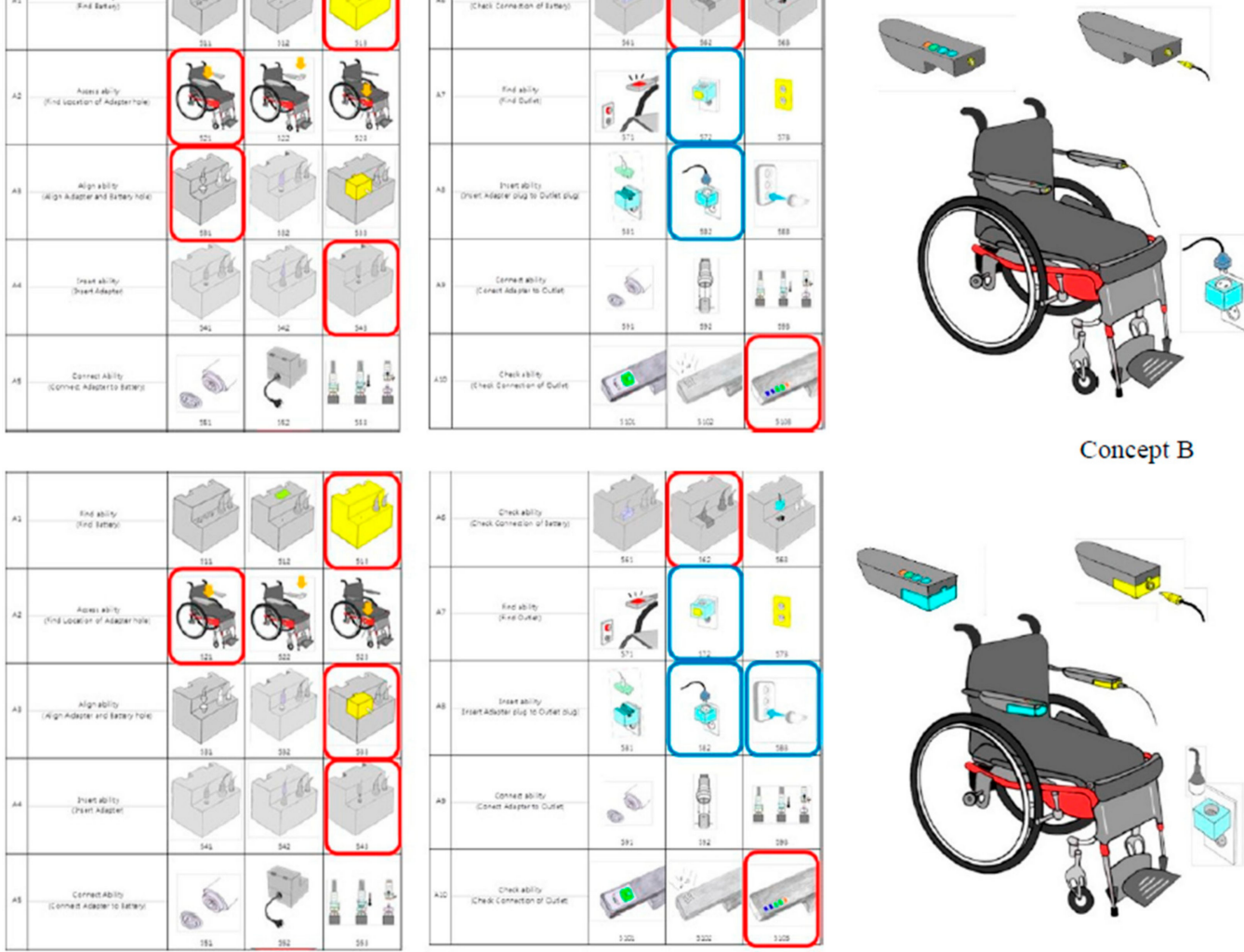

Concept B
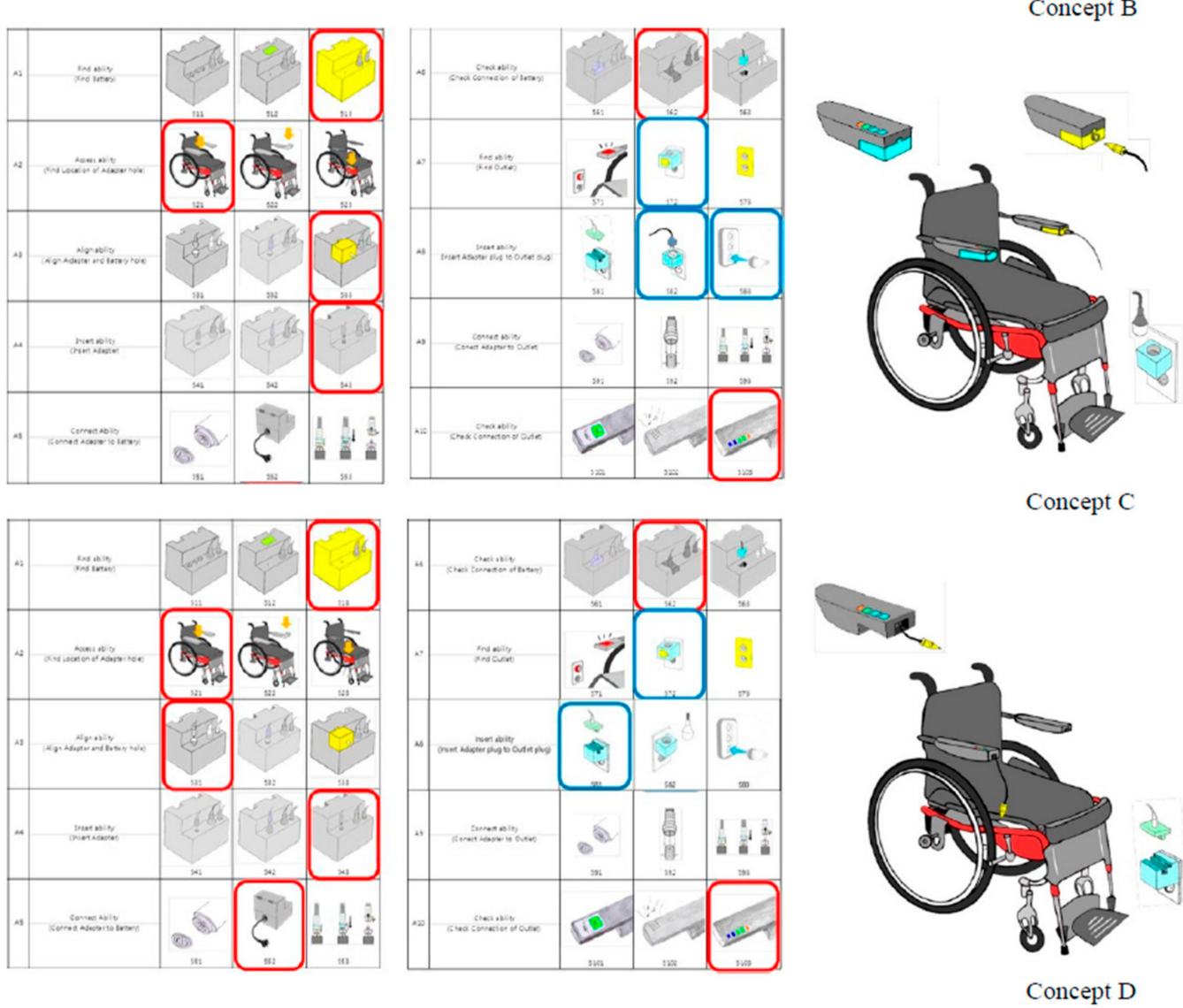

Figure 9. Concept Alternatives Generated Using Morphological Chart. 


\subsection{Concept Evaluation and Proposed Redesign Concept}

The four redesign concepts are evaluated using Pugh's concept selection method [35] with the original design as the standard for five-level relative comparison with,,$+++ \mathrm{S}$ (the same),,--- for each of the evaluation criteria as shown in Figure 10. Specific criteria for connecting the adaptor with the battery and with the power outlet were used as well for overall criteria including cost and product value issues.

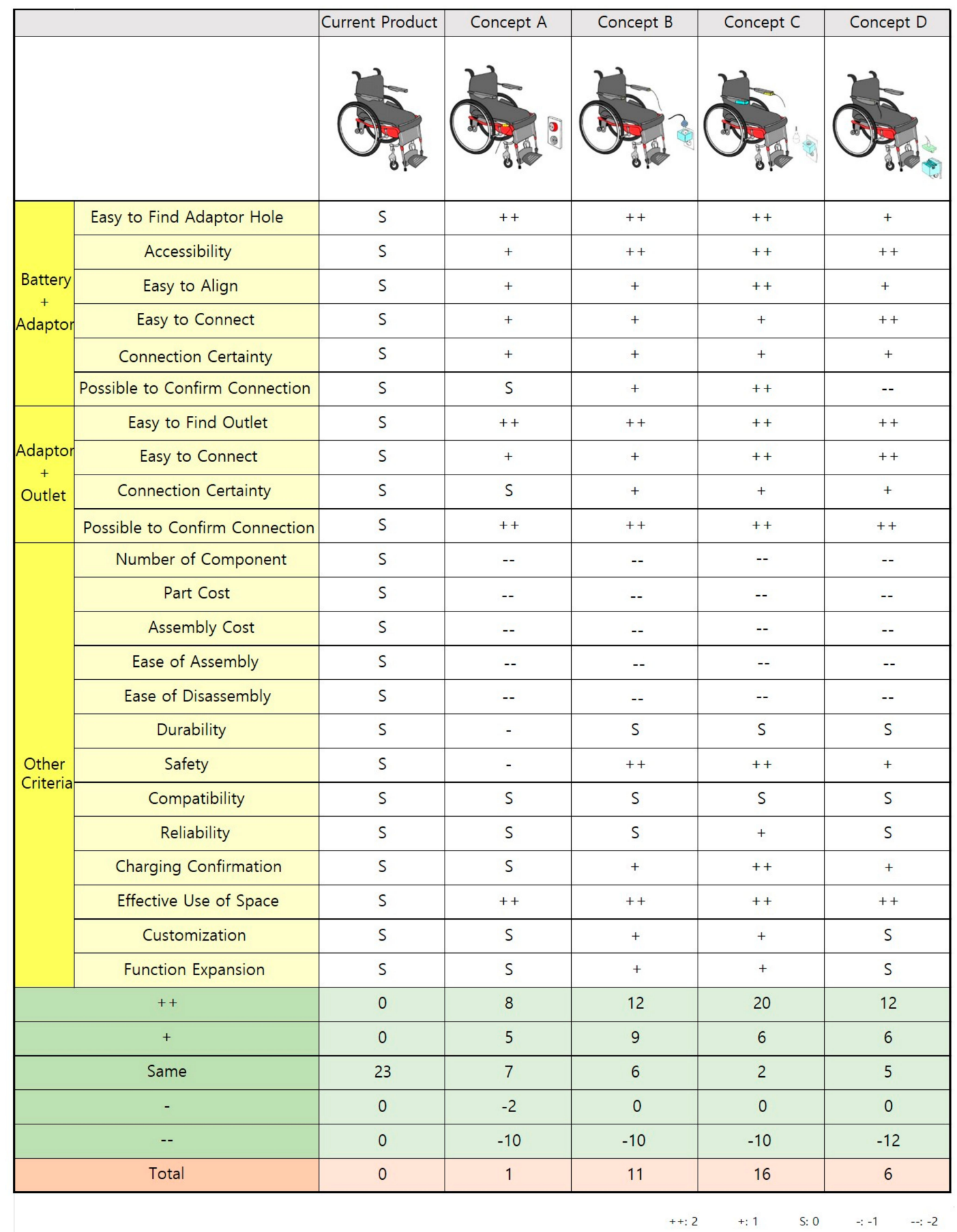

Figure 10. Service Evaluation of Concept Alternatives using Relative Comparison. 
As the affordances for charging service activities with connection functions were utilized, all redesign concepts are better than the original design. Concept $\mathrm{D}$ was determined to be not considerably easier in finding the adaptor hole due to the dangling string which made the confirmation bad as well. Concepts $C$ and $D$ were determined to be very easy to connect the adaptor to the outlet as they use the vertical downward insertion with simple mating features. Obviously, overall cost is increased for all redesign concepts, with additional components as well as increased assembly and disassembly cost.

Evaluation criteria such as effective space use and customization are important. The current design requires that charging service providers approach the wheelchair from the back, with lowering bodies because the battery is located under the seat. The physical action of connecting with the adaptor cable would not be easy. But all the redesign concepts allow an approach direction from the front, resulting in effective space use. While the distance of the wheelchair with the power outlet on the walls needs to be controlled short, the option of having the adaptor hole on either hand rest is a considerable improvement in the customization of charging service activities reflecting the physical context of the wall locations.

By summing up the criterion-wise comparisons, the overall comparative evaluations were made in which the concept design $C$ was chosen as the final concept, as shown in Figure 11. With such an accessible location of the adapter plug hole, not only the battery charging service provider but even the wheelchair user himself may access the plug. Concept $C$ provides flexibility with a proper approach orientation and proximity of the hand rest with power outlet. This results in a significant improvement as wheelchair users can charge the battery without helpers.

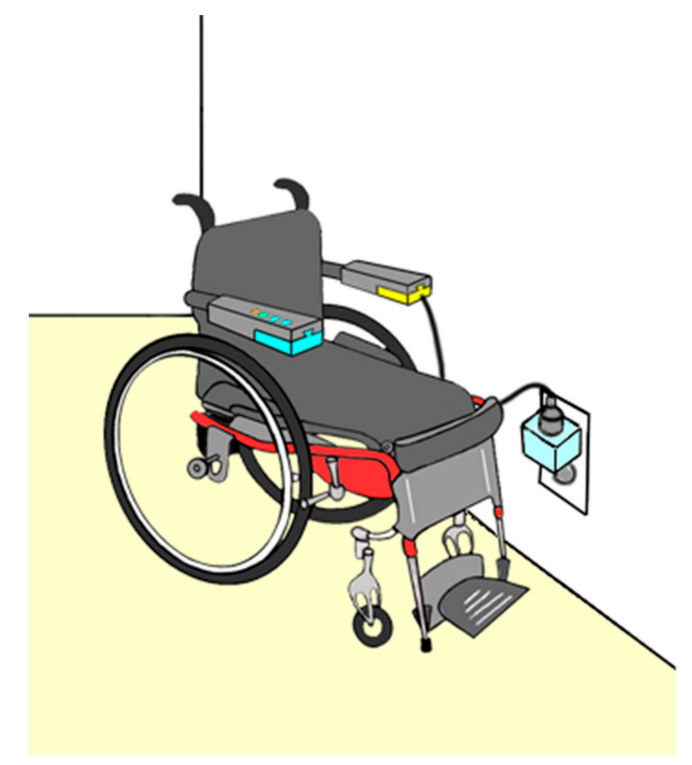

Figure 11. Standing Wheelchair Redesign for Charging Service.

This achieves enormous value enhancement. While the goal of this redesign was to design for service considerations, the resulting design also enables the user to self-serve the charging operation. This achieves value enhancement in economic value by not requiring a charging helper, but also in experience value of control with the user's capability of charging himself. As energy is needed to stand or to lift-up the user, the user would like to know the amount of remaining battery power while sitting on the wheelchair. Thus, a new feature of showing battery level would afford users to check the battery level. This not only enhances the epistemic value of information but also reduces mental burden and worry about the remaining amount of energy in both cases where a helper offers the charging service and the user self-serves. In this way, totally new activities and experiences could be enabled for the user and service providers during the use phase of the standing wheelchair through product redesign for service activities. 


\section{Discussion}

Humans use products and services to have a better life and to achieve various values. Product design has been addressing designing of functions and structures of things with the primary attention on users of the product. In product design, design for users or user-friendly design is important. User-product interaction issues are critical, and design for affordance $[3-5,8,38]$ is desirable. Then life-cycle design methods encompassing broader life-cycle issues have been developed in design for $\mathrm{X}$ methods, such as design for manufacture, design for assembly, design for product retirement, etc. Design for serviceability methods [9-11] address ease of services such as repair with an emphasis on the product aspects.

Recently, design for services [39], or service design, has received attention with the popularity of service-dominant logic [40] and emphasis on customer experiences. The objects of designing in service design are services, that is, human activities. Various newly designed services are combined with products in product-service systems to provide diverse values to users and other stakeholders. Product-service systems are often developed starting from products with new services added to provide various values. For design for $\mathrm{X}$, design method transformations are made from a product-centered approach to a human-centered approach [3]. For example, design for sustainability methods have evolved from a product innovation level to a product-service system innovation level, then to a socio-technical system innovation level [41]. Design for sustainable behavior [42] efforts has a higher emphasis on consumer activities and behavior. This could then evolve to encompass new services, educating and facilitating desirable consumption behaviors.

Coping with these transformations, new systematic methods to redesign products for considerations on various new services are desired with a focus on service activities in a service provider-centered approach. The proposed redesign method of this paper addresses this goal, which has not received much attention until recently. This would be regarded as design for service considerations or design for service activities. The objects of designing are products as in design for serviceability, but the approach deals with activities of service providers specifically through affordances which associate human activities and product features systematically. The proposed method realizes the activity-centered design approach [43], with rich description of service activities and context information using the CBAM method [27].

Please note that relevant services which the proposed design for service considerations cover would be much broader than repair and maintenance services, although the example case of the paper addressed a typical maintenance service of charging. Service activities would be various activities performed by other stakeholders than users for the product during life-cycle steps in use and post-use phases. More conventional service activities such as maintenance and repair are included, but many other life-cycle service activities are relevant as well, including operational services, information provision and education services promoting sustainable user behavior, rental and sharing services, remanufacturing and recycling services, and disposal services, all of which address diverse sustainability issues. The proposed method is novel in its utility: as long as service activities are identified, whether material or ecological issues are involved or not, product redesign is supported by identifying affordances relevant to service activities and by using affordance features.

The proposed redesign method provides a systematic framework of design processes of service activity modeling and function decomposition to devise affordances for service activities. Next, affordance feature design is realized through analogical reasoning using a repository of affordance features. The very nature of design is that designers should play critical roles in designing; the design method and supporting tools guide and enhance a designer's creative activities. Designers are responsible for creative analogical designing of affordance features and creative synthesizing in this divide and conquer method. Composing and managing the repository of affordance features is also important; this task is also to be done by designers or design teams by continued accumulation of acquiring, storing, and retrieving of knowledge and experiences in design for affordances. The CBAM method provides structured support for this task. 
The proposed method enhances through redesign of products diverse life-cycle services in which many stakeholders are participating to co-create values for societal, entrepreneurial, and ecological sustainability. Future research work would include incorporation of reconfigurable possibilities of products and service elements where functional contributions of some products elements and service elements can be interchanged. Along the mega trend of digital servitization [44,45], assessment of similarities of design constrains and context information could be supported by computational tools as the affordance feature repository accumulates massively. As context-specific evaluation of customer use experiences would enable customization of use experiences [46,47], service experience evaluation data can be acquired from service providers in conjunction with service affordances and diverse context information so that customization of service experiences could be pursued.

Author Contributions: All the authors contributed to all aspects of the research presented in this paper. Y.S.K. conceptualized and developed the design method for service considerations, led the design case, and wrote the manuscript. K.S. collaborated on the design case during the graduate study and reviewed and revised the manuscript. S.J.H. directed the research project, collaborated in the conceptualization of the method, coordinated and advised the design case, and reviewed and revised the manuscript. All authors have read and agreed to the published version of the manuscript.

Funding: This research was supported by the Korea Institute for Advancement of Technology under the project entitled the Product Development for Service Consideration (N0000876) conducted at the Korea National Cleaner Production Center and Sungkyunkwan University.

Conflicts of Interest: The authors declare no conflict of interest.

\section{References}

1. Gibson, J.J. The Theory of Affordances in the Ecological Approach to Visual Perceptual; Houghton Mifflin: Boston, MA, USA, 1979.

2. Norman, D.A. The Design of Everyday Things; Basic Books: New York, NY, USA, 2002.

3. Galvao, A.B.; Sato, K. Human-Centered System Architecture: A Framework for Interpreting and Applying User Needs. In Proceedings of the ASME 2004 International Design Engineering Technical Conferences and Computers and Information in Engineering Conference, Salt Lake City, UT, USA, 28 September-2 October 2004.

4. Galvao, A.B.; Sato, K. Affordances in Product Architecture: Linking Technical Functions and Users' Tasks. In Proceedings of the ASME 2005 International Design Engineering Technical Conferences and Computers and Information in Engineering Conference, Long Beach, CA, USA, 24-28 September 2005.

5. Galvao, A.B.; Sato, K. Incorporating Affordances into Product Architecture: Methodology and Case Study. In Proceedings of the ASME 2006 International Design Engineering Technical Conferences and Computers and Information in Engineering Conference, Philadelphia, PA, USA, 10-13 September 2006.

6. Kim, M.K.; Jeong, J.Y.; Kim, Y.S.; Lee, S.W. Identifying Affordance Features from User Activity Study. In Proceedings of the International Conference Design Computing \& Cognition, Atlanta, GA, USA, 23-25 June 2008.

7. Murakami, T.; Cheng, L.M.; Higuchi, M.; Yanagisawa, H. Trial for formulation of affordance feature for product design. In Proceedings of the Human Interface Symposium, Kurashiki, Okayama, Japan, 20-22 September 2006; pp. 403-408. (In Japanese)

8. Kim, Y.S. A Methodology of Design for Affordances using Affordance Feature Repositories. AI Eng. Des. Anal. Manuf. 2015, 29, 307-323. [CrossRef]

9. Gershenson, J.; Ishii, K. Design for Serviceabilty, Concurrent Engineering: Theory and Practice; John Wiley: New York, NY, USA, 1992; pp. 19-39.

10. Dewhurst, P.; Abbatiello, N. Design for Service. In Design for X; Huang, G.Q., Ed.; Springer: Dordrecht, The Netherlands, 1996.

11. Sodhi, R.; Sonnenberg, M.; Das, S. Evaluating the unfastening effort in design for disassembly and serviceability. J. Eng. Des. 2004, 15, 60-69. [CrossRef]

12. Ishii, K. Life-Cycle Engineering Design. J. Mech. Des. 1995, 117, 42-47. [CrossRef]

13. Alting, L. Life Cycle Engineering and Design. CIRP Ann. 1995, 44, 569-580. [CrossRef]

14. Stoll, H.W. Design for Manufacture: An Overview. ASME Appl. Mech. Rev. 1986, 39, 1356-1364. [CrossRef] 
15. Baines, T.; Lightfoot, H. Made to Serve: How Manufacturers Can. Compete Through Servitization and Product Service Systems; Wiley: Hoboken, NJ, USA, 2013.

16. Fischer, T.; Gebauer, H.; Fleisch, E. Service Business Development: Strategies for Value Creation in Manufacturing Firms; Cambridge University Press: New York, NY, USA, 2012.

17. Ulaga, W.; Reinartz, W. Hybrid Offerings: How Manufacturing Firms Combine Goods and Services Successfully. J. Mark. 2011, 75, 5-23. [CrossRef]

18. Goedkoop, M.J.; van Halen, C.J.G.; te Riele, H.R.M.; Rommens, P.J.M. Product Service Systems, Ecological and Economic Basics; The Dutch Ministries of Environment (VROM) and Economic Affairs (EZ): The Hague, The Netherlands, 1999.

19. Tukker, A. Eight Types of Product-Service Systems: Eight Ways to Sustainability? Experiences from SusProNet. Bus. Strategy Environ. 2004, 13, 246-260. [CrossRef]

20. Tan, A.R.; McAloone, T.C. Characteristics of Strategies in Product/Service-System Development. In Proceedings of the 9th International Design Conference, Dubrovnik, Croatia, 15-18 May 2006; pp. 1435-1442.

21. Schmitt, B. Experience Marketing: Concepts, Framework and Consumer Insights. Found. Trends Mark. 2011, 5, 55-112. [CrossRef]

22. Teixeira, J.; Patricio, L.; Nunes, N.; Nobrega, L.; Fisk, R.; Constantine, L. Customer experience modeling: From customer experience to service design. J. Serv. Manag. 2012, 23, 362-376. [CrossRef]

23. Rabetino, R.; Kohtamäki, M.; Lehtonen, H.; Kostama, H. Developing the concept of life-cycle service offering. Ind. Mark. Manag. 2015, 49, 53-66. [CrossRef]

24. Gaiardelli, P.; Resta, B.; Martinez, V.; Pinto, R.; Albores, P. A Classification Model for Product-Service Offerings. J. Clean. Prod. 2014, 66, 507-519. [CrossRef]

25. Kim, Y.S.; Lee, S.W.; Kim, S.R.; Jeong, H.; Kim, J.H. A Product-Service Systems Design Method with Integration of Product Elements and Service Elements Using Affordances. In Proceedings of the 3rd Service Design and Service Innovation Conference, Espoo, Finland, 8-10 February 2012.

26. Shostack, G.L. How to Design a Service. Eu. J. Mark. 1982, 16, 49-63. [CrossRef]

27. Kim, Y.S.; Lee, S.W. Service Design for Product-Service Systems Using Context-based Activity Modeling. In Proceedings of the International Association of Societies of Design Research (IASDR) Conference, Delft, The Netherlands, 31 October-4 November 2011.

28. Pahl, G.; Beitz, W. Engineering Design: A Systematic Approach; Springer: London, UK, 1988.

29. Kirschman, C.F.; Fadel, G.M. Classifying functions for mechanical design. J. Mech. Des. 1998, 120, 475-482. [CrossRef]

30. Zwicky, F. Morphological astronomy. Observatory 1948, 68, 121-143.

31. Cross, N. Engineering Design Methods—Strategies for Product Design; Wiley: Hoboken, NJ, USA, 2000.

32. Lee, J.H.; Shin, D.I.; Hong, Y.S.; Kim, Y.S. Business Model Design Methodology for Innovative Product-Service Systems: A Strategic and Structured Approach. In Proceedings of the International Conference on Engineering Design, Copenhagen, Denmark, 15-18 August 2011; Volume 4.

33. Kwon, M.; Lee, J.H.; Hong, Y.S. Product-Service System Business Modelling Methodology Using Morphological Analysis. Sustainability 2019, 11, 1376. [CrossRef]

34. Haber, N.; Fargnoli, M. Design for product-service systems: A procedure to enhance functional integration of product-service offerings. Int. J. Prod. 2017, 22, 135-164. [CrossRef]

35. Pugh, S. Concept Selection: A Method that Works. In Proceedings of the International Conference on Engineering Design, Rome, Italy, 9-13 March 1981; pp. 497-506.

36. Norman, D.A.; Ortony, A. Designers and Users: Two Perspectives on Emotion and Design. In Proceedings of the Symposium on Foundations of Interaction Design, Las Vegas, NV, USA, 21-26 July 2003.

37. Boothroyd, G.; Dewhurst, P.; Knight, W.A. Product Design for Manufacture and Assembly, 3rd ed.; CRC Press: Boca Raton, FL, USA, 2010.

38. Maier, J.R.A.; Ezhilan, T.; Fadel, G.M. The affordance structure matrix-A concept exploration and attention directing tool for affordance based design. In Proceedings of the ASME International Conference Design Theory and Methodology, Las Vegas, NV, USA, 4-7 September 2007.

39. Meroni, A.; Sangiorgi, D. Design for Services; Gower: Aldershot, UK, 2011.

40. Vargo, S.L.; Lusch, R.F. Evolving to a new dominant logic for marketing. J. Mark. 2004, 68, 1-17. [CrossRef]

41. Ceschin, F.; Gaziulusoy, I. Evolution of Design for Sustainability: From Product Design to Design for System Innovations and Transitions. Des. Stud. 2016, 47, 118-163. [CrossRef] 
42. Bhamra, T.; Lilley, D.; Tang, T. Design for Sustainable Behaviour: Using Products to Change Consumer Behaviour. Des. J. 2011, 14, 427-445. [CrossRef]

43. Gay, G.; Hembrooke, H. Activity-Centered Design: An Ecological Approach to Designing Smart Tools and Usable Systems; The MIT Press: Cambridge, UK, 2004.

44. Coreynen, W.; Matthyssens, P.; Van Bockhaven, W. Boosting Servitization through Digitization: Pathways and Dynamic Resource Configurations for Manufacturers. Ind. Mark. Manag. 2017, 60, 42-53. [CrossRef]

45. Isaksson, O.; Hallstedt, I.S.; Rönnbäck, Ö.A. Digitalisation, sustainability and servitisation: Consequences on product development capabilities in manufacturing firms. In Proceedings of the International Design Conference-Norddesign, Linköping, Sweden, 14-17 August 2018.

46. Kim, Y.S.; Hong, Y.K.; Kim, J.H.; Kim, Y.M. Context-Specific Experience Sampling for Experience Design Research. In Proceedings of the 18th International Conference on Engineering Design (ICED11), Lyngby/Copenhagen, Denmark, 15-18 August 2011.

47. Kim, Y.S.; Hong, Y.K. Systematic Method to Design Product-Service Systems Using Personalization Services based on Experience Evaluations. Int. J. Prod. Dev. 2019. accepted.

(C) 2019 by the authors. Licensee MDPI, Basel, Switzerland. This article is an open access article distributed under the terms and conditions of the Creative Commons Attribution (CC BY) license (http://creativecommons.org/licenses/by/4.0/). 